\title{
Power density dynamics in a nuclear reactor with an extended in-core pulse-periodic neutron source based on a magnetic trap
}

\author{
Igor V. Shamanin ${ }^{1}$, Sergey V. Bedenko ${ }^{1}$, Vladimir M. Shmakov², \\ Dmitry G. Modestov ${ }^{2}$, Igor O. Lutsik ${ }^{1}$ \\ 1 National Research Tomsk Polytechnic University, 30 Lenin Pr., 634050, Tomsk, Russia \\ 2 Federal State Unitary Enterprise «Russian Federal Nuclear Center-Zababakhin All-Russia Research Institute of Technical Physics», 13 Vasilyev \\ Ave., 456770, Snezhinsk, Russia
}

Corresponding author: Sergey V. Bedenko (bedenko@tpu.ru)

Academic editor: Georgy Tikhomirov • Received 5 March 2020 Accepted 20 June 2020 • Published 29 September 2020

Citation: Shamanin IV, Bedenko SV, Shmakov VM, Modestov DG, Lutsik IO (2020) Power density dynamics in a nuclear reactor with an extended in-core pulse-periodic neutron source based on a magnetic trap. Nuclear Energy and Technology 6(3): 175-179. https://doi.org/10.3897/nucet.6.57976

\begin{abstract}
The article examines the features of the spatial kinetics of an innovative hybrid nuclear power facility with an extended neutron source based on a magnetic trap. The fusion-fission facility under study includes a reactor plant, the core of which consists of an assembly of thorium-plutonium fuel blocks of the HGTRU reactor of a unified design and a long magnetic trap that penetrates the near-axial region of the core. The engineering solution for the neutron plasma generator is based on an operating gas-dynamic trap based on a fusion neutron source (GDT-FNS) developed at the Novosibirsk G.I. Budker Nuclear Physics Institute of the Siberian Branch of the Russian Academy of Sciences. The GDT-FNS high-temperature plasma pinch is formed in pulse-periodic mode in the investigated hybrid facility configuration, and, at a certain pulse rate, one should expect the formation of a fission wave that diverges from the axial part of the system and propagates throughout the fuel block assembly in a time correlation with the fast D-D neutron pulse source. In these conditions, it is essential to study the fission wave propagation process and, accordingly, the power density distribution formation within the facility blanket. The paper presents the results of a study on the steady-state and space-time performances of neutron fluxes and the power density dynamics in the facility under investigation. The steady-state neutronic performance and the space-time fission wave propagation were simulated using the PRIZMA software package developed at FSUE RFNC-VNIITF.
\end{abstract}

\section{Keywords}

Fission wave, D-D neutron plasma pulse periodic generator, fusion-fission hybrid reactor

\section{Introduction}

The article considers the features of the spatial kinetics of a hybrid thorium reactor plant with an extended fusion neutron source based on a gas-dynamic magnetic trap
(GDT-FNS). The fusion-fission reactor facility under study (Fig. 1 (Arzhannikov et al. 2019, 2019a)) is essentially a hybrid reactor, the core of which consists of an assembly of fuel blocks of a unified design of a high-temperature gas-cooled HGTRU reactor (Shamanin et al. 2018,

* Izvestiya vuzov. Yadernaya Energetika (ISSN 0204-3327), 2020, n. 2, pp. 17-26.

Copyright Shamanin IV et al. This is an open access article distributed under the terms of the Creative Commons Attribution License (CC-BY 4.0), which permits unrestricted use, distribution, and reproduction in any medium, provided the original author and source are credited. 
Bedenko et al. 2019) and a long magnetic trap that penetrates the near-axial region of the core (Yurov et al. 2012).

The long magnetic trap includes a neutral beam injection heating zone, a plasma column inside the assembly, and two parts with a multi-mirror magnetic field for minimizing longitudinal plasma energy losses along the axis of the plasma column. The engineering solution for the D-D (T) neutron plasma generator is based on an operating gas-dynamic multi-mirror magnetic trap developed at the Novosibirsk G.I. Budker Nuclear Physics Institute of the Siberian Branch of the Russian Academy of Sciences.

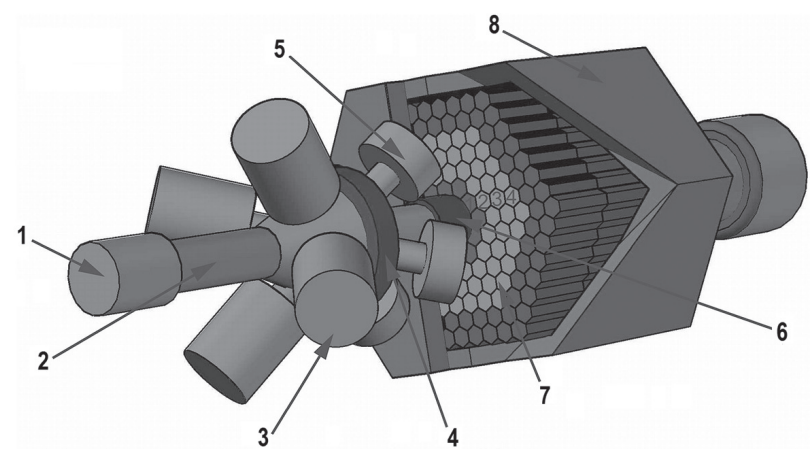

Figure 1. Conceptual design of the fusion-fission hybrid reactor facility: 1 - leaky plasma receiver; 2 - longitudinal plasma flow deceleration chamber; 3 - heating atomic beam injectors; 4 - plasma heating chamber; 5 - transmitted beam receiver; 6 - fusion neutron generation chamber; 7 - nuclear reactor fuel assembly; 8 - neutron shield.

In the investigated configuration of the hybrid installation, a high-temperature plasma pinch is formed in pulse-periodic mode in the investigated hybrid facility configuration, and, at a certain pulse rate, one should expect the formation of a fission wave that diverges from the axial part of the system and propagates throughout the fuel block assembly in a time correlation with the fast D-D neutron pulse source. In these conditions, it is essential to study the fission wave propagation process and, accordingly, the power density distribution formation within the facility. These studies will make it possible to optimize the active part of the system and to neutralize the arising offsets of the radial and axial power density fields in the fuel.

Speaking from the perspective of solving urgent applied problems of modern nuclear power, we can hope that the results of this study will form the basis for ensuring stable operation of hybrid systems controlled by an external pulse-periodic source of additional neutrons.

\section{Materials and methods}

\section{Computational model}

To study the fission wave propagation process, a detailed 3D model of the facility (Fig. 2 (Arzhannikov et al. 2019)) was simplified to an infinite two-layer cylinder with a central region intended for a D-D neutron plasma generator (Fig. 3).

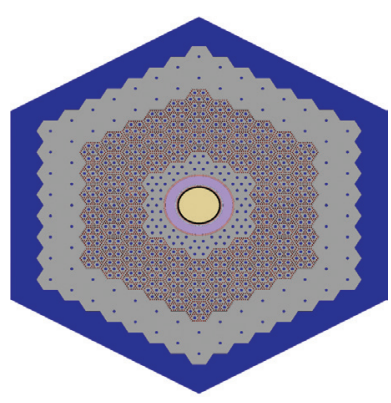

(a)

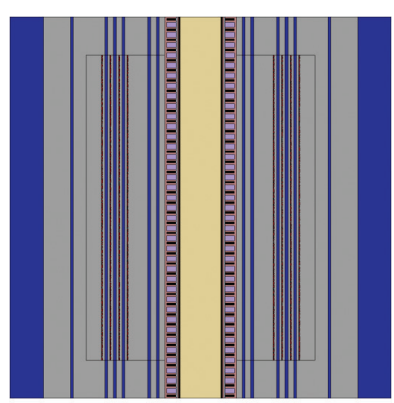

(b)
Figure 2. Detailed 3D model of the fusion-fission hybrid reactor facility: a) - cross section; b) - longitudinal section.

The computational model used in simulations is a cylindrically symmetric system infinite along the $O Z$ axis (Fig. 3), consisting of three areas bounded by radii of $30,118.34$ and $154.7 \mathrm{~cm}$. The height of the entire system is $100 \mathrm{~cm}$, with white mirror at the ends. In the inner region of the model system, is a fast D-D neutron pulse source (GDT-FNS); in the outer region, is a graphite reflector with a density of $2.2 \mathrm{~g} / \mathrm{cm}^{3}$. Between these regions, there is a core with homogenized $\mathrm{Th}_{(1-\mathrm{a})}{ }^{-}$ $\mathrm{Pu}$ fuel, consisting of 50 layers of equal volume. The initial nuclear composition of the homogenized region is shown in Table 1.

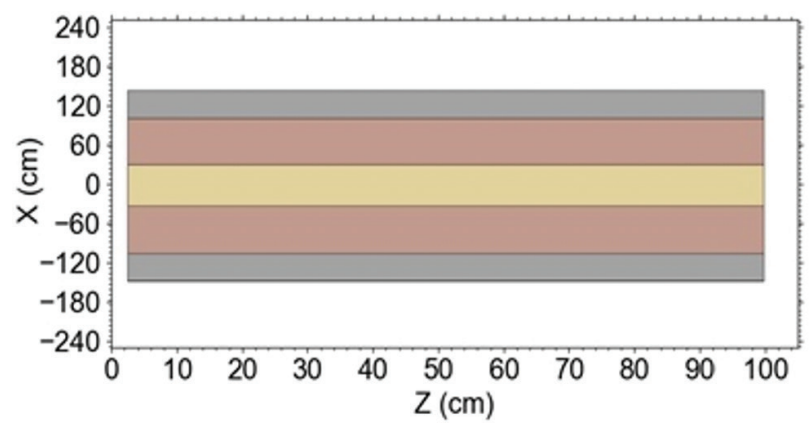

Figure 3. Computational 3D Model: longitudinal section of the model in the $X-Z$ plane.

Table 1. Composition of the homogenized fuel part of the facility blanket

\begin{tabular}{lc}
\hline \multicolumn{1}{c}{ Nuclide } & Nuclide concentration, nuclide/(b cm) \\
${ }^{232} \mathrm{Th}$ & $6.57 \mathrm{E}-5$ \\
${ }^{239} \mathrm{Pu}$ & $6.18 \mathrm{E}-5$ \\
${ }^{240} \mathrm{Pu}$ & $3.29 \mathrm{E}-6$ \\
${ }^{241} \mathrm{Pu}$ & $6.60 \mathrm{E}-7$ \\
${ }^{16} \mathrm{O}$ & $2.63 \mathrm{E}-4$ \\
${ }^{12} \mathrm{C}$ & $9.35 \mathrm{E}-2$ \\
$\mathrm{Si}$ & $1.36 \mathrm{E}-3$ \\
$\mathrm{Ti}$ & $3.41 \mathrm{E}-4$ \\
$\mathrm{He}$ & $2.53 \mathrm{E}-5$. \\
\hline
\end{tabular}




\section{Computational research methods}

The steady-state neutronic performance and the spacetime fission wave propagation were simulated using the PRIZMA software package (Kandiev et al. 2015), with the ENDF/B-VII.1 library of evaluated incident-neutron data (Nuclear Energy Agency acces. 2020), developed at FSUE RFNC-VNIITF.

To determine the steady-state neutronic characteristics $\left(k_{\text {eff }}(\mathrm{a})\right.$, where $\mathrm{a}$ is the Pu content), the calculations of the conditionally critical problem were carried out.

\section{Results}

\section{Steady-state neutronic characteristics}

The results of calculating the steady-state neutronic characteristics of the core modified for an additional D-D source are shown in Fig. 4 and Table 2.

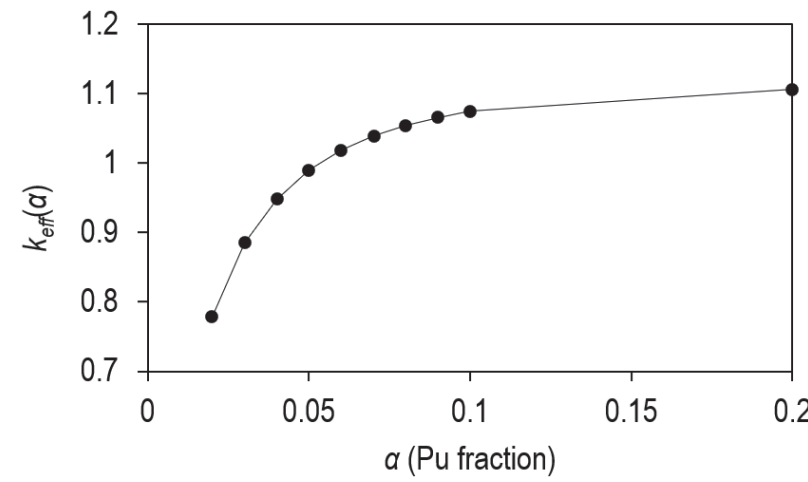

Figure 4. Dependence of the effective multiplication factor of the facility on the mass content of plutonium $\mathrm{Pu}(\mathrm{a})$ in the $\mathrm{Th}_{(1-\mathrm{a})^{-}}$ $\mathrm{Pu}_{\mathrm{a}}$ composition.

Table 2. Steady-state neutronic characteristics of the simulated system

\begin{tabular}{l|c|c|c|c|c|c}
\hline $\begin{array}{l}{ }^{232} \mathbf{T h}, \\
\text { wt.\% }\end{array}$ & \multirow{2}{*}{$\begin{array}{c}\text { Pu, } \\
\text { wt.\% }\end{array}$} & \multicolumn{6}{|c|}{ Nuclide concentration, nuclide/(b cm) } & \\
\cline { 3 - 7 } & & ${ }^{232} \mathbf{T h}$ & ${ }^{239} \mathbf{P u}$ & ${ }^{240} \mathbf{P u}$ & ${ }^{241} \mathbf{P u}$ & $\mathbf{k}_{\text {eff }}$ \\
\hline 96 & 4 & $1.90 \mathrm{E}-5$ & $1.10 \mathrm{E}-6$ & $2.10 \mathrm{E}-7$ & $5.09 \mathrm{E}-4$ & 0.9460 \\
\hline
\end{tabular}

The figure and the table clearly show that the selected composition provided $k_{\text {eff }}=0.95$ required for hybrid systems (Gudowsky et al. 2001, Moir et al. 2012, Simonen et al. 2013, Shmelev et al. 2015, Knastera et al. 2016, Velasquez et al. 2016). In this case, the plutonium content in the $\mathrm{Th}_{(1-\mathrm{a})}-\mathrm{Pu}$ a composition was $4 \%$.

\section{Space-time characteristics}

Fig. 5 shows the results of calculating the space-time characteristics of the facility (see Tab. at the time of its start-up with a 'cold' core. Five cross-sections reflect the fission wave propagation throughout the blanket from the axial region adjacent to the magnetic trap in the radial direction. The figure shows that the effect of the neutron source operating in pulse-periodic mode is noticeable in the adjacent layers and disappears no later than $0.01 \mathrm{~ms}$ at the periphery of the fuel graphite blocks of the facility blanket.

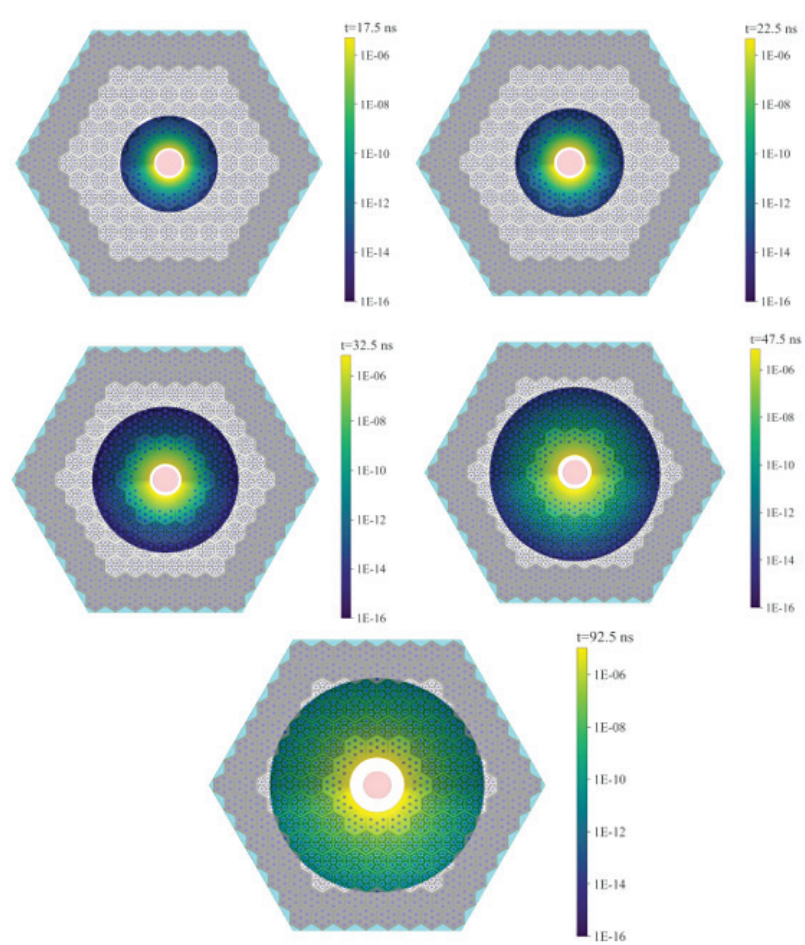

Figure 5. Power density dynamics in the fusion-fission facility.

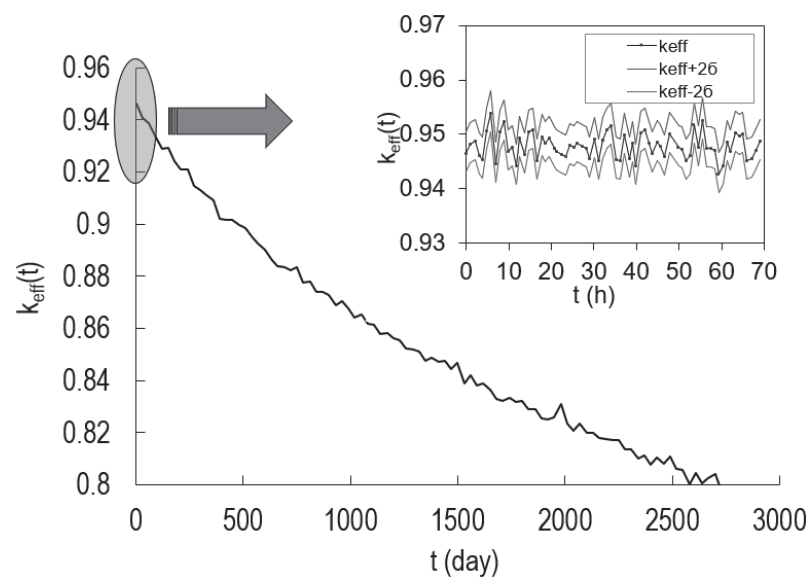

Figure 6. Dependence of the effective multiplication factor on the operating time of the fusion-fission facility.

After a single pulse of fast neutrons from the magnetic trap, the diffuse distribution of the fission density throughout the blanket is determined within a time interval of the order of $0.1 \mathrm{~ms}$, and the time to reach a steady state is $0.1 \mathrm{~s}(100 \mathrm{~ms})$. The simulation results showed that the solution of the further neutronic problem (i.e., finding $k_{e f f}(t)$ and other required neutron-physical functionals) is admissible by replacing the pulse-periodic neutron source 
(pulse duration $1 \mathrm{~ms}$ and pulse ratio 2) with a constantly acting quasi-steady-state one.

Fig. 6 shows the results of calculating the $k_{\text {eff }}(t)$ dependence for a long-term irradiation regime and an irradiation time from $0.1 \mathrm{~s}$ to 3000 days.

The results shown in Fig. 6 confirm that:

- the selected composition ensured long-term operation of the facility; and

- to maintain $k_{\text {eff }}(t)$ at a constant level, the D-D source must feed the core with neutrons; in this case, the intensity of neutron generation $I_{\mathrm{n}}$ should rise smoothly (Fig. 7) during the entire fuel campaign.

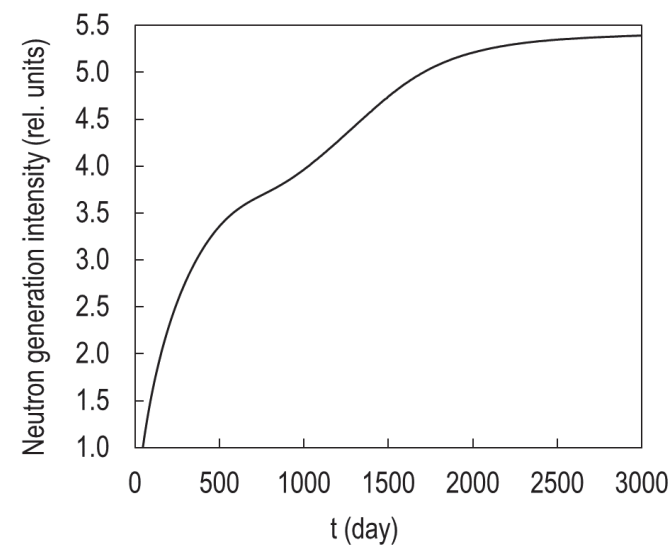

Figure 7. Increase in the GDT-FNS neutron production rate depending on the operating time of the fusion-fission facility.

\section{Conclusion}

The effect of the gas dynamic trap (GDT-FNS) operating in pulse-periodic mode is noticeable in the adjacent blanket layers and disappears no later than $0.01 \mathrm{~ms}$ at the periphery of the fuel part of the facility blanket.

During the start-up of the facility for the 'cold' blanket, the GDT-FNS should provide a stable intensity of D-D neutron generation in the range from $1 \times 10^{16}$ to $2 \times 10^{18}$ neutrons per second from the entire plasma column.

With a pulse duration of $1 \mathrm{~ms}$ and a pulse rate of 2 , GDT-FNS, operating in the required range of D-D-neutron generation, will provide blanket heating at a rate of $\mathrm{K} \times \mathrm{h}^{-1}$, which meets the requirements for compliance with thermal engineering reliability when starting from a 'cold' state.

To maintain $k_{\text {eff }}(t)$ at a constant level, the D-D source must feed the core with neutrons; in this case, the intensity of D-D-neutron generation should rise smoothly during the entire fuel campaign.

The results obtained in the work confirm the possibility of using the PRIZMA software package developed at FSUE RFNC - VNIITF to provide the entire list of fullscale calculations of the neutronic characteristics of the hybrid facility with the fusion neutron source operating in various modes.

This work was supported by the Russian Foundation for Basic Research. Grant No. 19-29-02005 mk.

\section{References}

- Anikeev AV, Bagryansky PA, Beklemishev AD, Ivanov AA, Korobeinikova OA, Kovalenko YuV, Lizunov AA, Maximov VV, Murakhtin SV, Pinzhenin EI, Prikhodko VV, Savkin V, Soldatkina EI, Solomakhin AL, Yakovlev DV, Zaytsev KV (2015) The GDT Experiment: Status and Recent Progress in Plasma Parameters. Fusion Science and Technology 68(1): 1-7. https://doi.org/10.13182/ FST14-867

- Arzhannikov A, Bedenko S, Shmakov V, Knyshev V, Lutsik I, Prikhodko V, Shamanin I (2019) Gas-cooled thorium reactor at various fuel loadings and its modification by a plasma source of extra neutrons. // Nuclear Science and Techniques 30(181): 1-11. https:// doi.org/10.1007/s41365-019-0707-y

- Arzhannikov AV, Anikeev AB, Beklemishev AD, Ivanov AA, Shamanin IV, D'Yachenko AN, Dolmatov OYu (2016) Subcritical Assembly with Thermonuclear Neutron Source as Device for Studies of Neutron-physical Characteristics of Thorium Fuel. AIP Conference Proceedings 1771(090004): 1-5. https://doi.org/10.1063/1.4964246

- Arzhannikov AV, Shamanin IV, Bedenko SV, Knyshev VV, Lutsik IO, Prikhodko VV (2019a) Hybrid Thorium Energy Producing Subcritical Facility with a Fusion Neutron Source Based on a Magnetic Trap. Izvestia vuzov. Yadernaya Energetika [News of Higher Educational Institutions. Nuclear Power Engineering] 2: 43-54. https://doi. org/10.26583/npe.2017.1.06 [in Russian]
Bagryansky P, Chen Z, Kotelnikov I, Yakovlev D, Prikhodko V, Zeng Q, Bai Y, Yu J-H, Ivanov A, WuY (2020) Development Strategy for Steady-state Fusion Volumetric Neutron Source Based on the Gas-dynamic Trap. Nuclear Fusion 60(036005): 1-15. https:// doi.org/10.1088/1741-4326/ab668d

- Bedenko SV, Ghal-Eh N, Lutsik IO, Shamanin IV (2019) A Fuel for Generation IV Nuclear Energy System: Isotopic Composition and Radiation Characteristics. Applied Radiation and Isotopes 147: 189-196. https://doi.org/10.1016/j.apradiso.2019.03.005

- Beklemishev A, Anikeev A, Astrelin V, Bagryansky P, Burdakov A, Davydenko V, Gavrilenko D, Ivanov A, Ivanov I, Ivantsivsky M, Kandaurov I, Polosatkin S, Postupaev V, Sinitsky S, Shoshin A, Timofeev I, Tsidulko Yu (2013) Novosibirsk Project of Gas-Dynamic Multiple-Mirror Trap. Fusion Science and Technology 63(1T): 46-51. https:// doi.org/10.13182/FST13-A16872

- Gudowsky W, Arzhanov V, Broeders C, Broeders I, Cetnar J, Cummings R, Ericsson M, Fogelberg B, Gaudard C, Koning A, Landeyro P, Magill J, Pazsit I, Peerani P, Phlippen P, Piontek M, Ramström E, Ravetto P, Ritter G, Shubin Y, Soubiale S, Toccoli C, Valade M, Wallenius J, Youinou G (2001) Review of the European Project - Impact of Accelerator-Based Technologies on Nuclear Fission safety (IABAT). Progress in Nuclear Energy 38(1-2): 135-151. https://doi.org/10.1016/S0149-1970(00)00099-8 
- Kandiev YZ, Kashaeva EA, Khatuntsev KE (2015) PRIZMA Status. Annals of Nuclear Energy 82: 116-120. https://doi.org/10.1016/j. anucene.2014.09.006

- Knastera J, Arbeiter F, Cara P, Chel S, Facco A, Heidinger R, Ibarra A, Kasugai A, Kondo H, Miccichè G, Ochiai K, Ohira S, Okumura Y, Sakamoto K, Wakai E (2016) IFMIF, the European-Japanese Efforts Under the Broader Approach Agreement Towards a Li(d,xn) Neutron Source: Current Status and Future options. Nuclear Materials and Energy 8: 46-54. https://doi.org/10.1016/j.nme.2016.04.012

- Moir RW, Martovetsky NN, Molvik AW, Ryutov D, Simonen TC (2012) Mirror-based Hybrids of Recent Design. AIP Conference Proceedings 1442: 43-54. https://doi.org/10.1063/1.4706853

- Nuclear Energy Agency (2020) Nuclear Energy Agency. https://oecdnea.org/dbdata/data/nds_eval_libs.htm [accessed Mar 03, 2020].

- Shamanin IV, Chertkov YB, Bedenko SV, Mendoza O, Knyshev VV, Grachev VM (2018) Neutronic Properties of High-temperature Gascooled Reactors with Thorium Fuel. Annals of Nuclear Energy 113 286-293. https://doi.org/10.1016/j.anucene.2017.11.045
- Shmelev AN, Kulikov GG, Kurnaev VA, Salahutdinov GH, Kulikov EG, Apse VA (2015) Hybrid Fusion-Fission Reactor with a Thorium Blanket: Its Potential in the Fuel Cycle of Nuclear Reactors. Physics of Atomic Nuclei 78: 1100-1111. https://doi.org/10.1134/ S1063778815100117

- Simonen TC, Moir RW, Molvik AW, Ryutov DD (2013) A 14 MeV Fusion Neutron Source for Material and Blanket Development and Fission Fuel Production. Nuclear Fusion 53(063002): 1-5. https:// doi.org/10.1088/0029-5515/53/6/063002

- Velasquez CE, Pereira C, Veloso MAF, Costa AL, Barros G de P (2016) Fusion-Fission Hybrid Systems for Transmutation. Journal of Fusion Energy 35: 505-512. https://doi.org/10.1007/s10894-0160080-3

- Yurov DV, Anikeev AV, Bagryansky PA, Brednikhin SA, Frolov SA, Lezhnin SI, Prikhodko VV (2012) Parameters Optimization in a Hybrid System with a Gas-dynamic Trap-based Neutron Source. Fusion Engineering and Design 87: 1684-1692. https://doi.org/10.1016/j. fusengdes.2012.07.005 